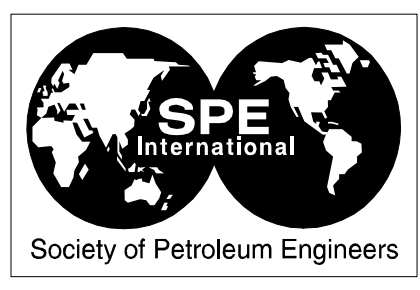

SPE 69844

\title{
Two-fluid Mixing Enhancement by Using a Static Turbulence Generator
}

\author{
Ortega P., McGrath G., Rojas-Solórzano L. \\ PDVSA-INTEVEP-Venezuela and Universidad Simon Bolivar, Caracas-Venezuela
}

Copyright 2001, Society of Petroleum Engineers Inc.

This paper was prepared for presentation at the 2001 SPE International Thermal Operations and Heavy Oil Symposuim held in Porlamar, Venezuela, 12-17 March 2001.

This paper was selected for presentation by an SPE Program Committee following review of information contained in an abstract submitted by the author(s). Contents of the paper, as presented, have not been reviewed by the Society of Petroleum Engineers and are subject to correction by the author(s). The material, as presented, does not necessarily reflect any position of the Society of Petroleum Engineers, its officers, or members. Papers presented a SPE meetings are subject to publication review by Editorial Committees of the Society of Petroleum Engineers. Electronic reproduction, distribution, or storage of any part of this pape for commercial purposes without the written consent of the Society of Petroleum Engineers is prohibited Permission to reproduce in print is restricted to an abstract of not more than 300 pords; illustrations may not be copied. The abstract must contain conspicu words; ilustrations may not be copied. The abstract must contain conspicuous

Box 833836, Richardson, TX 75083-3836, U.S.A., fax 01-972-952-9435.

\section{ABSTRACT}

The numerical simulation of a static T-type mixer for turbulent mixing of miscible liquids is reported. The simulation was carried out using CFX, a commercial computational fluid dynamic simulator. The effect of mixing intensification caused by turbulence generators placed downstream of the injection point of the Tee was evaluated in terms of reduction in mixing length for a given mixture quality, uniformity of turbulence intensity and efficiency of energy conversion to useful mixing energy.

The mixing quality for an intensified and conventional T-type mixer was compared, and the turbulence generator geometry was optimized. Main stream Reynolds numbers between 50000 and 100000 were considered for additive volume ratios in the range $0.1-10 \%$. Selected simulations were validated with experimental data available in the literature for conventional smooth T-type mixers (no ribs).

Results were in good agreement with experimental correlations available at high Reynolds numbers.

Simulations demonstrated that mixing enhancement was efficient with turbulence generators, extending the Reynolds number range for which compact, low pressure-drop devices may be used for intense mixing. The optimum geometry for turbulence generators was evaluated using criteria based on energetic and spatial efficiency and in all cases the simple Tee was used as the point of reference.

Finally, practical design correlations are presented to enable the mixing quality of two miscible streams to be estimated for a simple Tee with and without additional turbulence generators over a range of Reynolds numbers and injection conditions.

\section{INTRODUCTION}

Turbulence is related with most of the industrial processes such as: chemical reactions, combustion, heat transfer operations and the mixing processes, among others. Mixing of miscible liquids is a process of multiple uses in the industry. The dilution of crudes, mixture of crudes, dilution of 
concentrated acids, water treatment (i.e. chlorination), surfactant dissolution and mud preparation for drilling are some of the applications of this technology. The mixing phenomenon occurs when two or more phases are in contact and mass is transferred from one phase to the other at a molecular level.

The main objective of this work is to study the effect that a turbulence generator has in the quality of mixing through the coefficient of variation, $\mathbf{C v}$, a measure of the homogeneity of the mixture. A good mixture implies the achievement of a homogeneous distribution of the components with respect to certain volume or to the cross-section of a pipe.

The particular interest of this work is to develop designing tools, such as graphics, charts and correlations, useful to determine the parameters of a mixing process for miscible liquids in a pipeline.

The designing tool will help the user in the selection of a geometry based on the costs for pressure drop against the required dimensionless distance (L/D), in order to achieve a uniform mixture downstream in a mixing process.

\section{THEORY}

Forney and Kwon (1979) derived a scaling law from an approximate solution of the momentum equations for flow in jets of normal impact on a fully developed flow. In their study, they supposed that the quality of mixing was independent of the Reynolds number of the impinging jet. Later on, Sroka and Forney (1989) carried out a theoreticalexperimental study on the mixing of two miscible liquids in pipes, by using a tee (T) arrangement injection for turbulent flow. It was found that the quality of mixing is affected only for the turbulent properties as the flow is developed downstream of injection point. Also, the quality of the mixing increases as the momentum of the jet is increased.
Forney, et al. (1996), carried out a study that includes a numerical simulation for the optimization of mixing using a tubular reactor jet type. As seen in their previous studies, the second moment of the tracer was used in order to quantify the mixing quality. It was observed that the mixing does not depend so much on the flow regime, but on the momentum of the incident jet at the injection point.

Myers (1997) published a work in which the use of the High Efficiency Vortex (HEV) is discussed. No design tools are presented. The use of this mixer is for high Reynolds numbers.

In none of the previous work, neither the effects of turbulence generation to improve the quality of mixing is discussed, nor the existence of curves for design that could help the user to choose a geometry based on the pressure drop costs or required mixing distance has been presented.

\section{COMPUTACIONAL SIMULATION}

In the numerical simulations for the mixing process, the commercial CFX 4.2 code was used. This computational fluid dynamic tool works in finding an approximate solution to the continuity, momentum conservation, and species conservation equations, using the finite volume control method.

The method of finite volume subdivides the domain of the problem in several control volumes whose centers are called nodes, i.e., for each specified node in the domain; there is a control volume in its surroundings. The governing differentiatial equations are integrated for each one of these control volumes, where a discrete equation is obtained. This equation relates each variable in the center of the control volume with its surroundings.

The solution method for the differentiatial equations turns into solving a set of equations.

\section{Equations for the Modeling}

The mathematical model used was a single-phase multi-component model. For this study, it was assumed that the fluids in both flow currents were 
incompressible, Newtonian, and miscible. Therefore, the equations (all written in a vectorial form with some simplifications for the given conditions) to be solved were as follows:

The continuity equation for an incompressible fluid:

$$
\nabla \cdot u=0
$$

The momentum conservation equation for each substance, to take into account the velocity profiles:

$$
\frac{\partial u}{\partial t}+(\vec{u} \cdot \nabla) \vec{u}=-\frac{\nabla p}{\rho}+v \nabla^{2} u
$$

The mass fraction, $\mathbf{Y}_{\mathbf{i}}$ for species "i" is governed by the conservation of the species equation, as follows:

$\frac{\partial \rho Y_{i}}{\partial t}+\nabla \cdot\left\{\rho \cdot U \cdot Y_{i}-\left(\Gamma_{i}+\frac{\mu_{T}}{\sigma_{i}}\right) \nabla Y_{i}\right\}=0$

Where, "U" is the instantaneous velocity, "p" is the pressure, " $\Gamma_{\mathbf{i}}=\boldsymbol{D}_{\mathbf{i}}^{*} \rho$ " is the molecular diffusion coefficient for species "i" (the substance to be mixed) multiplied by the density of the background fluid, " $\rho "$ ". "Y $\mathbf{Y}_{\mathbf{i}}$ is the mass fraction for the substance "i," which is related with the molar concentration, $\mathbf{X}_{\mathbf{i}}$ and is calculated with the following equation:

$$
Y_{i}=\frac{W i^{*}\left[X_{i}\right]}{\rho}
$$

Similarly, " $\sigma \mathbf{i}$ " is the turbulent Prandlt number for the substance "i" and " $\nabla$ " is the Nabbla vectorial operator.

In equation (5), “ $\mu_{\mathrm{T}}$ ” represents the turbulent viscosity contribution to the mixing process, and can be modeled by the expression (Solver Manual CFX 4.2 (1997)):

$\mu_{T}=\frac{C \mu^{*} \rho^{*} \kappa^{2}}{\varepsilon}$

where, $\mathbf{C} \boldsymbol{\mu}=0.09$ (as an empirical value).

Turbulent contributions were accounted with the $\kappa-\varepsilon$ model, which applies for a wide range of flow regimes. Also, $\kappa-\varepsilon$ RNG model was used to account for wall boundary effects. Here, the kinetic turbulent energy $(\kappa)$ is related with the energy dissipation rate $(\varepsilon)$.

The transport equations for $\kappa-\varepsilon$, (after simplifications) are as follows:

For $\kappa$ :

$$
\frac{\partial \rho \kappa}{\partial t}+\nabla \cdot(\rho U \kappa)-\nabla \cdot\left(\left(\mu+\frac{\mu_{T}}{\sigma k}\right) \nabla k\right)=p+\rho \varepsilon
$$

For $\varepsilon$ :

$$
\frac{\partial \rho \varepsilon}{\partial t}+\nabla \cdot(\rho U \varepsilon)-\nabla \cdot\left(\left(\mu+\frac{\mu_{T}}{\sigma_{\varepsilon}}\right) \nabla k\right)=C 1 \frac{\varepsilon}{\kappa} p+C 2 \rho \frac{\varepsilon^{2}}{\kappa}
$$

Where C1 and C2, are constant coefficients, defined in the solver manual for CFX 4.2 (1997).

\section{Proposed Design for the Apparatus}

In Figure 1 the design for the new mixer is described. An injection stream for the additive $(\mathbf{q})$ is fed into the background fluid flow (Q). A Turbulence generator is placed on the upper and lower part of the inside walls of the pipe, leaving an open space in between $\left(\mathbf{G}_{\mathbf{R}}\right)$ to reduce the pressure drop. Turbulence is promoted and mixing is enhanced.

\section{Mesh Refinement}

A refinement on the mesh size was performed by doing a sensitive analysis on the variables of interest such as pressure and variation coefficient by running simulations with $\mathbf{d} / \mathbf{4}, \mathrm{d} / \mathbf{5}$ and $\mathrm{d} / \mathbf{8}$ (a fraction of the injection pipe diameter, 1-in) mesh sizes. It was found that an uniform mesh size of $\mathbf{d} / \mathbf{5}$ gave less than $3 \%$ of variation on these variables, as seen in Table 1. Therefore, this was the value used as the mesh size.

A total of 65,000 grids were used. A sample of the meshing is shown in Figure 2.

\section{RESULTS}

In following sections results will be presented and discussed in detail.

\section{Validation with experimental correlations}

Simulations were validated against an experimental correlation discussed by McGrath 
(1998). A comparison between simulation and experimental correlation results using three sampling points located $120^{\circ}$ apart and at D/3 from the wall, was performed.

Results shown in Table 2, indicate less than 3\% of variation in the mixing quality (Cv). Simulation was carried out under conditions similar to the ones the correlation was developed for.

Also, a validation with the theoreticalexperimental correlation (shown in Figure 3) developed by Sroka and Forney (1989) was carried out. Results from simulations shown in Figure 4, indicate good agreement with the work done by Sroka and Forney.

\section{Mixing quality Simulation in a pipeline}

Figure 5 shows a mixing quality simulation in a conventional empty pipe, (cep ). In order to reach an acceptable mixing quality $\left(\mathrm{C}_{\mathrm{v}}=5 \%\right)$, a dimensionless length (L/D) of 120 diameters downstream is required.

On the other hand, a simulation shown in Fig. 6 (same conditions as for a conventional pipe) indicates that when placing a rib $\left(G_{R} / D=20 \%\right)$ downstream of the injection point, the required $\mathbf{L} / \mathbf{D}$ to reach $\mathrm{C}_{\mathrm{v}}=5 \%$ can be reduced from 120 to 30 diameters (75\% length reduction).

\section{Feeding ratio effects on mixing quality}

The feeding ratio effects are presented in Fig. 7. As the feeding ratio decreases, the mixing quality improves. Data correlate according to the expression, Ortega (2000):

$$
C_{V}=2.0529 *\left(\frac{Q}{q}\right)^{0.1667} * \operatorname{Exp}\left(-0.04407 * \frac{L}{D}\right)
$$

where, $\mathbf{Q} / \mathbf{q}$ is the feeding ratio, and $\mathbf{L} / \mathbf{D}$ is the dimensionless distance from injection point. It was assumed a constant friction factor (Darcy) $\mathrm{f}_{\mathrm{D}}=0.030$, which applies for a smooth pipe in the high turbulent region. Reynolds number was constant at $\operatorname{Re}=1 \times 10^{5}$. In Fig. 7, doted line indicates the optimum mixing quality $\left(\mathrm{C}_{\mathrm{V}}=5 \%\right)$.

\section{Geometry effects on mixing quality}

The open space between the upper and lower ribs was studied. Figure 8 shows that mixing quality becomes better as the open space $\left(\mathbf{G}_{\mathbf{R}}\right)$ is reduced because more turbulence is promoted. Data correlate as follows, Ortega (2000):

$$
C_{V}=1.9767 *\left(\frac{G_{R}}{D}\right)^{1.538} * \operatorname{Exp}\left(-0.0292 * \frac{L}{D}\right)
$$

Where, $\mathbf{G}_{\mathbf{R}} / \mathbf{D}$ is the dimensionless space between the upper and lower ribs as seen in Fig. 1.

\section{Flow regime effects on mixing quality}

Flow regime does not affect the mixing quality as much as the open space. In Fig. 9, it can be seen that for Reynolds number from 50000 to 100000 , when open space is $G_{R} / D=0.20$, the dimensionless length, to reach $5 \%$ of homogeneity does not change. Feeding ratios were varied from $Q / q=33.3$ to $\mathrm{Q} / \mathrm{q}=100$.

\section{Open space effects on pressure drop}

As it was expected, pressure drop increases as the open space is reduced, as seen in Fig. 10. The higher the Reynolds number, the greater the pressure drop. Therefore, there is a trade off between the desired mixing quality and the pressure drop, which will be discussed in the next section.

\section{Curves for design: The contribution of this work}

Most of the time the available space in a plant is limited. Therefore, required mixing length prediction is important. Design curves in Fig. 11 become very helpful in predicting the optimum mixing operational point. For one side, the pressure ratio $\left(\Delta \mathbf{P}_{\mathbf{m}} / \Delta \mathbf{P}_{\text {cep }}\right)$ represents excess of pressure drop from a mixing process taking place in a conventional empty pipe (no ribs) to reach the same 
mixing quality $(\mathrm{Cv}=5 \%)$. Data correlate as follows, Ortega (2000):

$$
p r=\frac{\Delta P_{m}}{\Delta P_{\text {cep }}}=61.674 *\left(\frac{G_{R}}{D}\right)^{-1.0225}
$$

Where, $\Delta \mathbf{P}_{\mathbf{m}}$ is the pressure drop caused by the mixer, and $\Delta \mathbf{P}_{\text {cep }}$ is the pressure drop caused by the conventional empty pipe.

On the other hand, the length ratio ( $\left.\mathbf{L} \mathbf{D}_{\mathbf{m}} / \mathbf{L} \mathbf{D}_{\mathbf{c e p}}\right)$ has to do with the length that would be saved using the new mixer compared with a mixing process being carried out in a conventional empty pipe. Data correlates as follows, Ortega (2000):

$L D=\frac{\Delta L D_{m}}{\Delta L D_{\text {cep }}}=0.8795 *\left(\frac{G_{R}}{D}\right)^{-2.364}$

As seen in Fig. 11, the optimum mixing operational point is around $33 \%$ of the open space $\left(\mathbf{G}_{\mathbf{R}} / \mathbf{D}\right)$. This is the point where the designer can save space and the pumping costs are not too high.

\section{CONCLUSIONS}

Using a static turbulence generator, a lot of space can be saved (i.e. pipe length) in an industrial or experimental facility.

Mixing quality becomes better as the open space $\left(G_{R} / D\right)$. between the upper and lower turbulence generator is reduced.

Design curves indicate that the optimum mixing operational point for design is around $\mathrm{G}_{\mathrm{R}} / \mathrm{D}=0.33$.

In general, simulation results were in good agreement with correlations in literature.

\section{NOMENCLATURE}

$\mathrm{C}_{\mathrm{V}} \quad$ Variation coefficient

D Main pipeline diameter, [m]

$D_{\mathrm{i}} \quad$ Molec. diffusion coef. for specie “i”, [m²/s]

$\mathrm{d} \quad$ Injection pipe diameter, [m]

$\mathrm{f}_{\mathrm{D}} \quad$ Darcy's friction factor

$\mathrm{G}_{\mathrm{R}} \quad$ Open space between ribs, [m]

$\mathrm{H}_{\mathrm{F}} \quad$ Rib font height, [m]

$\mathrm{H}_{\mathrm{R}} \quad$ Rib final height, [m]

L Pipe length, [m]

LD Dimensionless mixing length
$\mathrm{LD}_{\mathrm{m}} \quad$ Dimensionless mixing length for new mixer

$\mathrm{LD}_{\text {cep }}$ Dimensionless mixing length for a conventional empty pipe

$\mathrm{L}_{\mathrm{R}} \quad$ Rib length, [m]

$\mathrm{U}$ o u Velocity in " $\mathrm{x}$ ” direction, $[\mathrm{m} / \mathrm{s}]$

$\mathrm{p}$ Pressure, $[\mathrm{Pa}]$

$\mathrm{Q} \quad$ Vol. flow rate in main pipeline, $\left[\mathrm{m}^{3} / \mathrm{s}\right]$

q Vol. flow rate in injection pipeline, $\left[\mathrm{m}^{3} / \mathrm{s}\right.$ ]

$\mathrm{t}$ Time, [s]

$\mathrm{W}_{\mathrm{E}} \quad$ Rib final width, [m]

$\mathrm{W}_{\mathrm{F}} \quad$ Rib front width, [m]

$Y_{i} \quad$ Mass Fraction for specie “i”"

$\mathrm{Y}_{\mathrm{m}} \quad$ Average mass fraction for specie "i"

$\mathrm{Z}_{\mathrm{R}} \quad$ Rib position from injection point, [m]

\section{Greek Letters}

$\varepsilon \quad$ Turbulent dissipation rate, [W/Kg]

$\Delta \mathrm{P} \quad$ Pressure drop, [Pa]

$\Delta \mathrm{P}_{\mathrm{m}} \quad$ Pressure drop in the new mixer, [Pa]

$\Delta \mathrm{P}_{\text {сер }}$ Pressure drop in the empty pipe, [Pa]

$\kappa \quad$ Turbulent kinetic energy, $\left[\mathrm{m}^{2} / \mathrm{s}^{2}\right]$

$\mu \quad$ Molecular viscosity, [Pa.s]

$\mu_{\mathrm{T}} \quad$ Turbulent viscosity, [Pa.s]

$\nabla \quad$ Nabbla vectorial operator

$v \quad$ Kinematics viscosity, $\left[\mathrm{m}^{2} / \mathrm{s}\right]$

$\rho \quad$ Background fluid density, $\left[\mathrm{Kg} / \mathrm{m}^{3}\right]$

$\Gamma_{\mathrm{i}} \quad$ Special diffusion coef., $\Gamma_{\mathrm{i}}=D_{\mathrm{i}}^{*} \rho,[\mathrm{Kg} /(\mathrm{m} . \mathrm{s})]$

$\sigma_{i} \quad$ Turbulent Prandtl number for specie "i”"

\section{REFERENCES}

1.- Forney, L.J., y Kwon, T.C. Efficient Single-Jet Mixing in Turbulent Tube Flow. AIChE. Journal. Vol. 25, No 4. (Julio1979).

2.- Sroka, L.M., y Forney, L.J., Fluid Mixing with a Pipeline Tee: Theory and Experiment. AIChE Journal. Vol. 35, No 3 (March 1989).

3.- Forney, L.J., Nafia, N. y Hanh, X.Vo. Optimum Jet Mixing in a Tubular Reactor. AIChE. Journal. Vol. 42, No 11. (November). (1996)

4.- Myers, K.J., Bakker, A. y Ryan D.,Avoid Agitation by Selecting Static Mixers. Chemical Engineering Progress. June (1997). 
5.- CFX-4.2, Solver Manual, AEA Technology

Engineering software, Inc. (1997).

6.- McGrath, G. Notas del curso: Mezclado en la

Industria Petrolera. PDVSA-INTEVEP, (1998)

Chapter 2.

7.- Ortega, P. Influencia de Generadores de Turbulencia en la Calidad de Mezclado de Liquidos Miscibles en Línea. M.S. Thesis Universidad Simon Bolivar- Caracas-Venezuela, (2000). 


\section{APPENDIX FOR TABLES AND FIGURES}

\begin{tabular}{|c|c|c|c|c|c|}
\hline \multicolumn{6}{|c|}{ TABLE 1. Sensitive analysis for mesh refinement } \\
\hline $\begin{array}{c}\text { Downstream } \\
\text { Length } \\
\text { L/D }\end{array}$ & $\begin{array}{c}\mathbf{C}_{\mathbf{v}} \\
\text { Grid } \\
\mathbf{d} / \mathbf{4}\end{array}$ & $\begin{array}{c}\mathbf{C}_{\mathbf{v}} \\
\text { Grid } \\
\mathbf{d} / \mathbf{5}\end{array}$ & $\begin{array}{c}\mathbf{C}_{\mathbf{v}} \\
\text { Grid } \\
\mathbf{d} / \mathbf{8}\end{array}$ & $\begin{array}{c}\text { Change } \\
\mathbf{d} / \mathbf{4}-\mathbf{d} / \mathbf{5} \\
{[\%]}\end{array}$ & $\begin{array}{c}\text { Change } \\
\mathbf{d} / \mathbf{5}-\mathbf{d} / \mathbf{8} \\
{[\mathbf{\%}]}\end{array}$ \\
\hline 5 & 1.065 & 1.138 & 1.163 & 8.4 & $\mathbf{2 . 1}$ \\
\hline 10 & 0.762 & 0.814 & 0.812 & 6.2 & $\mathbf{0 . 2}$ \\
\hline 20 & 0.505 & 0.547 & 0.534 & 5.4 & $\mathbf{2 . 4}$ \\
\hline 30 & 0.365 & 0.395 & 0.385 & 5.2 & $\mathbf{2 . 6}$ \\
\hline$\Delta \mathrm{P}$ & $-576 \mathrm{~Pa}$, & $-594 \mathrm{~Pa}$, & $-597 \mathrm{~Pa}$, & 3.1 & $\mathbf{0 . 5 1}$ \\
{$[0-30] \mathrm{D}$} & $-0.08 \mathrm{psi}$ & $-0.09 \mathrm{psi}$ & $-0.09 \mathrm{psi}$ & & \\
\hline
\end{tabular}

\begin{tabular}{|c|c|c|c|c|c|c|}
\hline \multicolumn{6}{|c|}{ TABLE 2. Simulation compared to an experimental correlation } \\
\hline $\begin{array}{c}\text { Feeding } \\
\text { Ratio, } \\
\text { Q/q }\end{array}$ & 10 & 100 & 200 & $\begin{array}{c}\text { Q/q=10 } \\
\text { Change } \\
\text { Corr } \\
\text { vs } \\
\text { Sim }\end{array}$ & $\begin{array}{c}\text { Q/q=100 } \\
\text { Change } \\
\text { Corr } \\
\text { vs } \\
\text { Sim }\end{array}$ & $\begin{array}{c}\text { Q/q=200 } \\
\text { Change } \\
\text { Corr } \\
\text { vs } \\
\text { Sim }\end{array}$ \\
\hline $\begin{array}{c}\text { Length, L/D to } \\
\text { reach Cv=5\%, } \\
\text { [Correlation] }\end{array}$ & 137 & 169 & 179 & & & \\
\hline $\begin{array}{c}\text { Length, L/D to } \\
\text { reach Cv=5\%, } \\
\text { [Simulation] }\end{array}$ & 134 & 172 & 174 & $2.19 \%$ & $1.74 \%$ & $2.79 \%$ \\
\hline
\end{tabular}

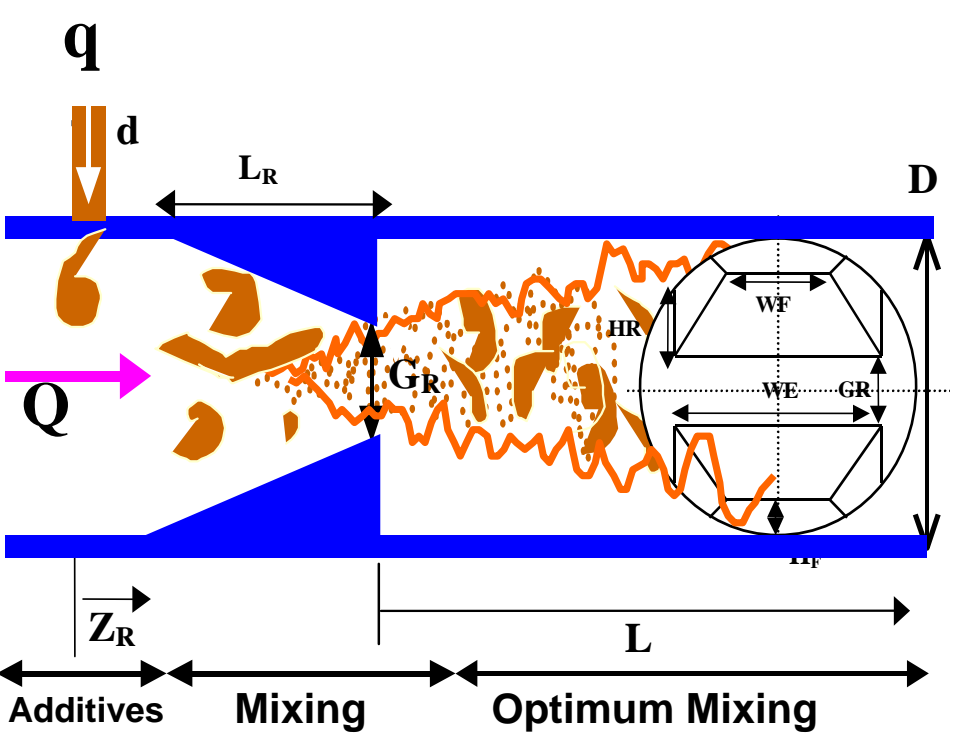

Figure 1. Schematic for the apparatus (mixer) with a pipe cross-section where turbulence generator geometry is described.

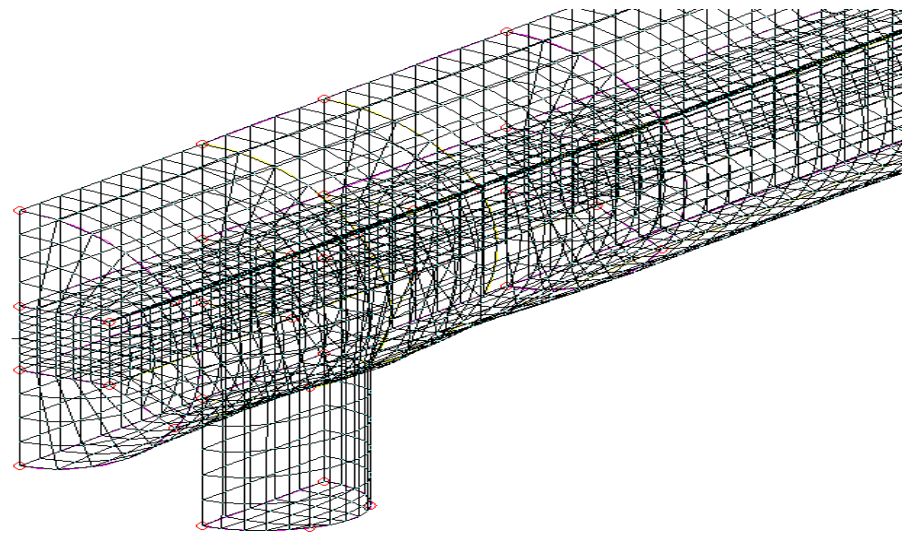

Figure 2. Mesh sample for a half of the pipe.

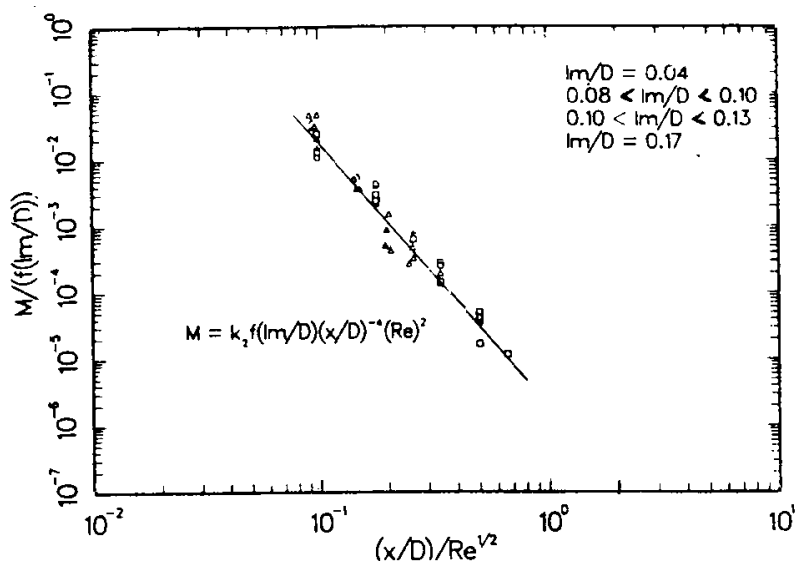

Figure 3. Sroka and Forney correlation results

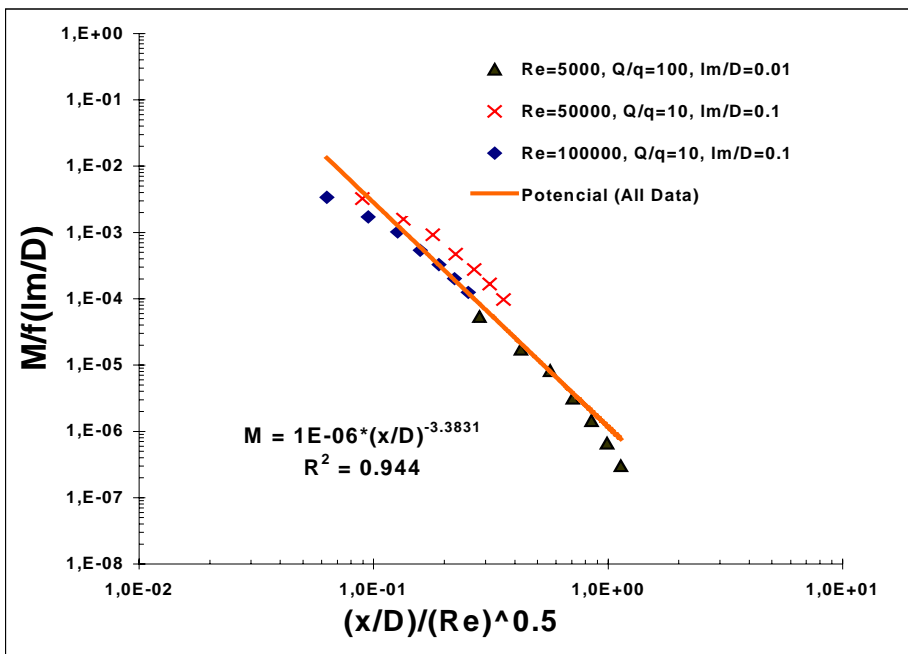

Figure 4. Results from Simulations 


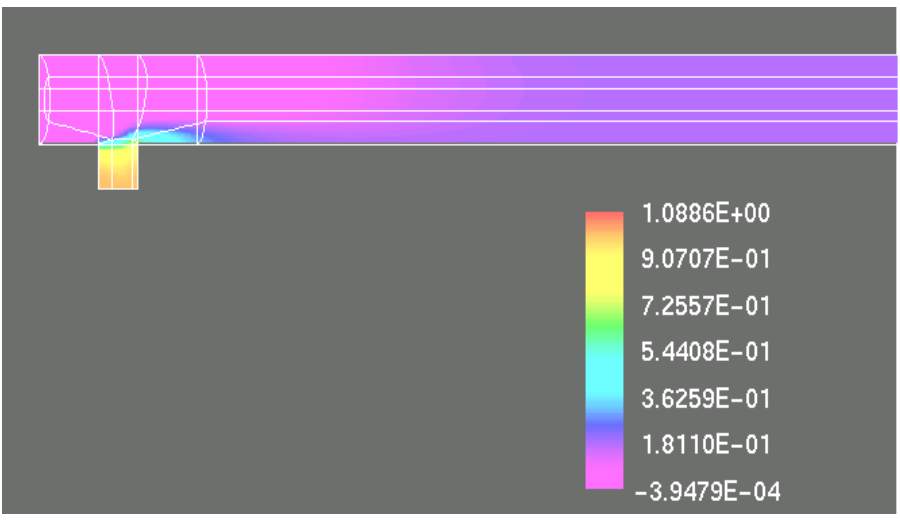

Figure 5. Mixing quality CFX simulation for a conventional empty pipe (no ribs). For $\operatorname{Re}=1 \times 10^{5}$

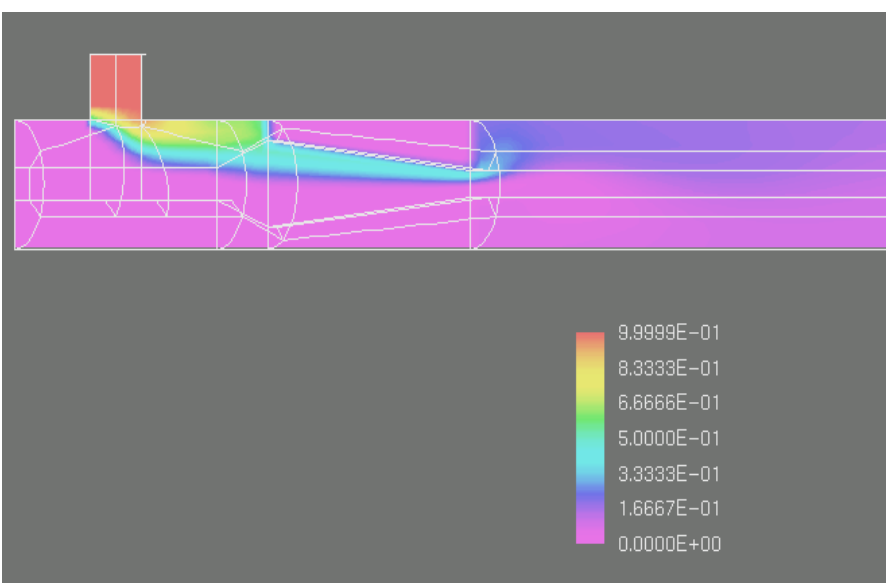

Figure 6. Mixing quality CFX simulation for pipe with a turbulence generator, $G_{R} / D=0.25$. For $\operatorname{Re}=1 \times 10^{5}$.

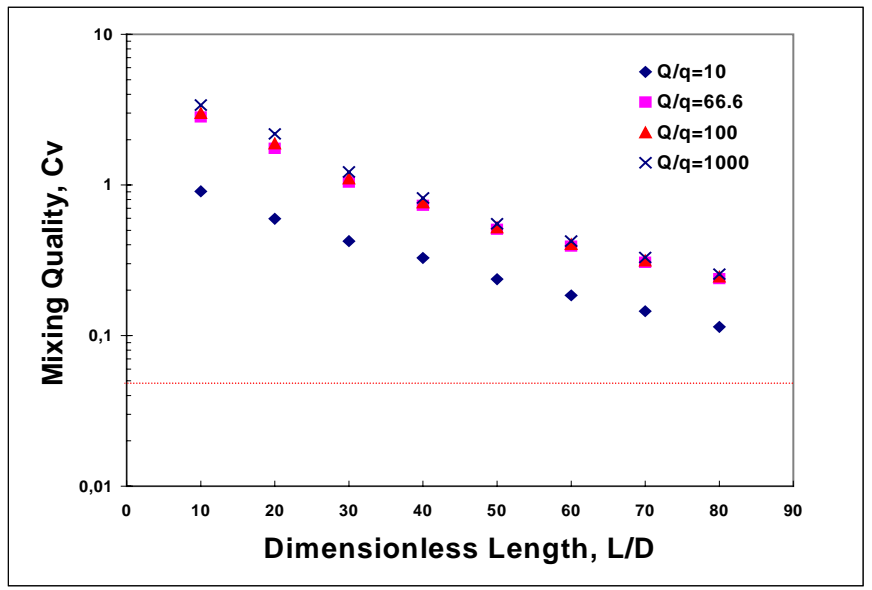

Figure 7. Mixing quality simulation data as a function of the feeding ratio in a conventional empty pipe. Reynolds in main line was kept constant at $\operatorname{Re}=1 \times 10^{5}$.

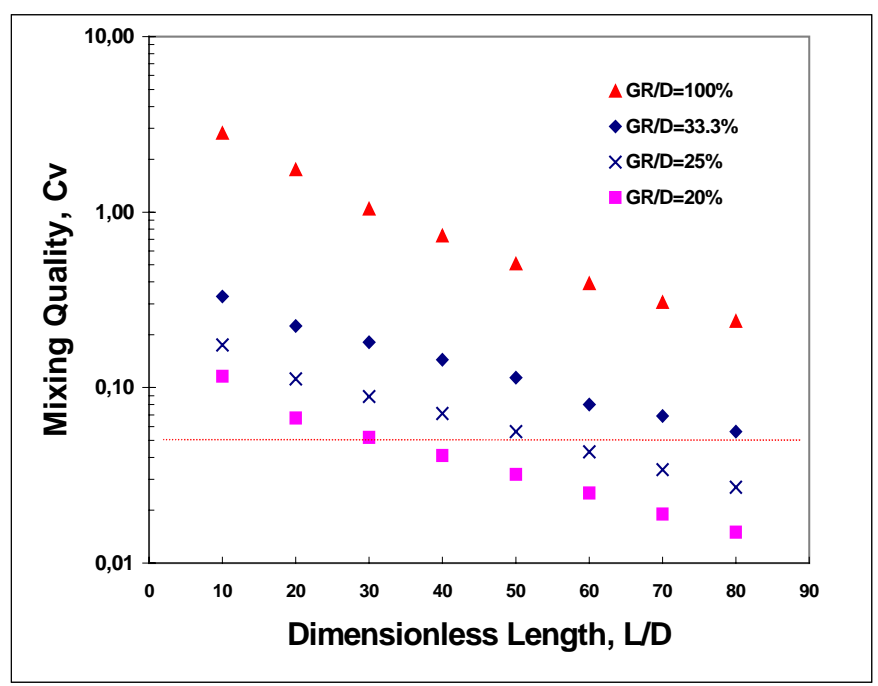

Figure 8. Mixing quality simulation data as a function of the open space $\left(G_{R}\right)$ between the upper and lower ribs. Feeding ratio and Re were kept at $Q / q=66.7$ and $R e=1 \times 10^{5}$, respectively.

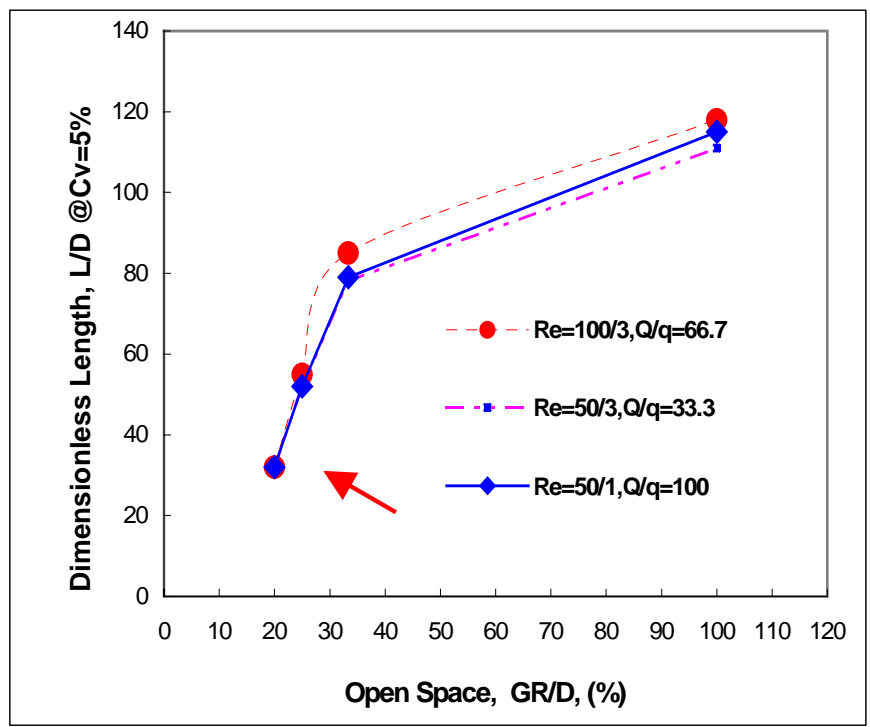

Figure 9. Mixing quality simulation data as a function of the flow conditions. 


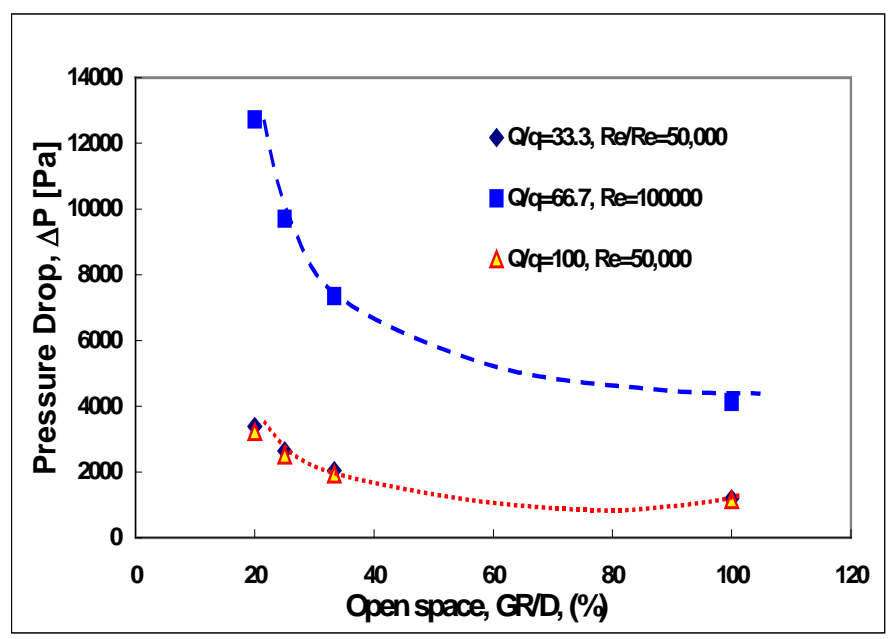

Figure 10. Pressure drop as a function of the open space between upper and lower ribs.

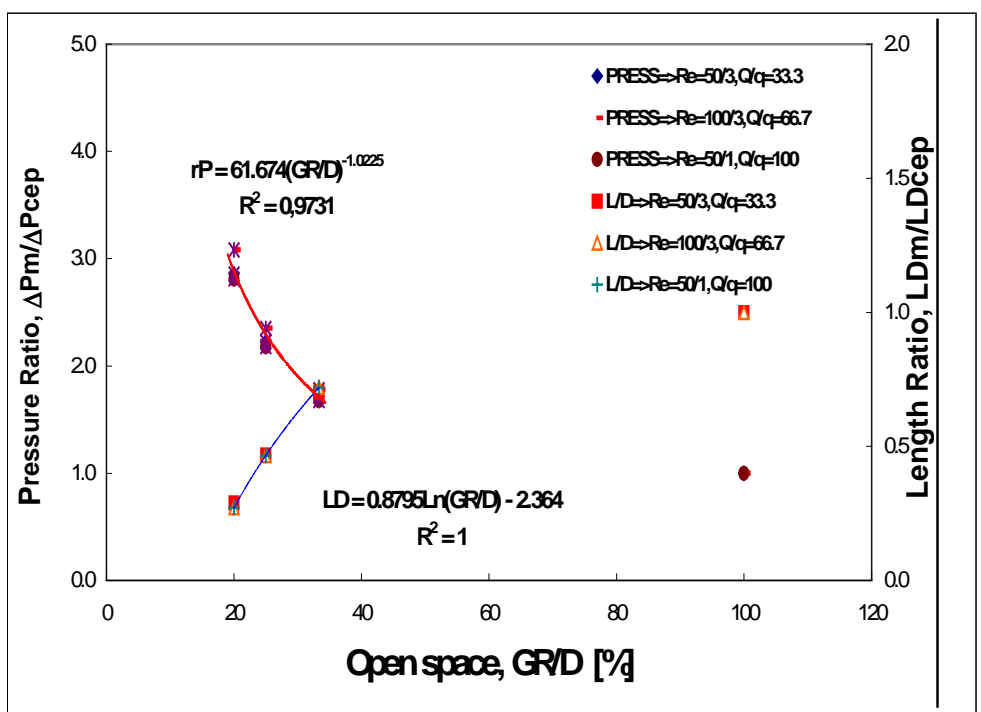

Figure 11. Design Curves for prediction of excess of pressure drop $(\Delta \mathrm{P})$ or saving in the required mixing length (LD). 